\title{
Affective stance, ambivalence, and psychophysiological responses during conversational storytelling
}

\section{Voutilainen, Liisa}

2014-07

Voutilainen , L , Henttonen , P , Kahri , M , Kivioja , M , Ravaja , N , Sams , M \& Perakyla , A 2014 , ' Affective stance, ambivalence, and psychophysiological responses during conversational storytelling ' , Journal of Pragmatics , vol. 68 , pp. 1-24 . https://doi.org/10.1016/j.pragma.2014.04.006

http://hdl.handle.net/10138/136237

https://doi.org/10.1016/j.pragma.2014.04.006

acceptedVersion

Downloaded from Helda, University of Helsinki institutional repository.

This is an electronic reprint of the original article.

This reprint may differ from the original in pagination and typographic detail.

Please cite the original version. 


\title{
Affective stance, ambivalence, and psychophysiological responses during conversational storytelling
}

\author{
Liisa Voutilainen ${ }^{a,{ }^{*}}$, Pentti Henttonen ${ }^{a}$, Mikko Kahri ${ }^{a}$, Maari Kivioja ${ }^{b}$, \\ Niklas Ravaja ${ }^{\mathrm{c}, \mathrm{d}}$, Mikko Sams ${ }^{\mathrm{e}}$, Anssi Peräkylä ${ }^{\mathrm{a}}$ \\ ${ }^{a}$ Finnish Centre of Excellence in Research on Intersubjectivity in Interaction, P.O. Box 4, 00014 University of Helsinki, Finland \\ ${ }^{\mathrm{b}}$ Outward Psychiatric Clinic of Western Helsinki, P.O. Box 6600, 00099 City of Helsinki, Finland \\ ${ }^{\mathrm{c}}$ Department of Social Research and Helsinki Institute for Information Technology, P.O. Box 54, \\ 00014 University of Helsinki, Finland \\ d School of Business, Aalto University, Finland \\ ${ }^{e}$ Brain and Mind Laboratory, Department of Biomedical Engineering and Computational Science, \\ Aalto University School of Science, P.O. Box 12200, 00076 Espoo, Finland
}

Received 4 July 2013; received in revised form 4 March 2014; accepted 15 April 2014

\begin{abstract}
Earlier research has shown that conversational storytelling is a regular locus for displays of affective stance. A stance display by the teller invites a mirroring response from the recipient, and these reciprocal displays are finely organized and timed. The article adds a new aspect to the research on affective stance and affiliation by examining the linkages between interactional stance displays and physiological responses in the participants. We show that the valence, and especially ambivalence, of the stance displayed by the storyteller is associated with an increase in the autonomic nervous system (ANS) activity in the recipient. The participants were 40 students who were discussing their life events in dyads. Heart rate, electrodermal activity (skin conductance), and facial muscle activity (EMG) of the participants were measured. The conversations were videotaped, and the storytelling instances were coded by means of a quantitative application of conversation analysis. The stories were coded into three classes: happy, sad, and ambivalent (twofold) stories on the basis of the affective stance that was displayed by the teller. In comparison to a happy and sad stance, ambivalence increased significantly the recipient's heart rate and electrodermal activity. Our interpretation is that the increased ANS activity reflects the more complex cognitive and interactional task faced by the recipients in affiliating with an ambivalent stance.
\end{abstract}

(c) 2014 Elsevier B.V. All rights reserved.

Keywords: Emotion; Ambivalence; Autonomic nervous system activity; Storytelling; Psychophysiology; Conversation analysis

\section{Introduction}

\subsection{Affective stance in storytelling}

Storytelling is common activity in mundane social life (see e.g. Labov and Waletzky, 1967; Barthes, 1977), and one of the principal ways in which people share their personal experiences (Jefferson, 1978). In the context of research on spoken stories and their reception in naturally occurring interaction, Stivers $(2008,32)$ conceptualized storytelling as "an activity that both takes a stance toward what is being reported and makes the taking of a stance by the recipient relevant".

\footnotetext{
* Corresponding author. Tel.: +358 503175586.

E-mail addresses: liisa.voutilainen@helsinki.fi (L. Voutilainen), pentti.henttonen@helsinki.fi (P. Henttonen), mikko.kahri@helsinki.fi (M. Kahri), niklas.ravaja@helsinki.fi (N. Ravaja), mikko.sams@aalto.fi (M. Sams), anssi.perakyla@helsinki.fi (A. Peräkylä).
} 
In this context, the term stance refers to the teller's affective treatment of the events he or she is talking about, or in a broad sense, to the emotional valence of the events as expressed by the teller (Sorjonen and Peräkylä, 2012: 5). Instances of storytelling are thus one regular locus for reciprocal displays of emotion, and they have proven to be rich materials for empirical research on interactional regulation of emotion (see e.g. Jefferson, 1978; Stivers, 2008; Ruusuvuori and Peräkylä, 2009; Peräkylä and Ruusuvuori, 2012; Couper-Kuhlen, 2012; Selting, 2010; Kupetz, 2014).

Earlier conversation analytical research has shown that the organization of storytelling, as well as displays of affective stance within it, have recurring structures and timing. Sacks (1974) described three basic sequences of a story: preface, telling sequence and response sequence (cf. Labov and Waletzky, 1967). Through initiating a story in a preface, the teller gets the floor for the telling sequence, in which the recipient typically refrains from taking a longer turn before the story gets to its completion and makes a full response relevant. During the telling phase, it is interactionally preferred that the recipient supports the process of telling by minimal responses (Sacks, 1974; Jefferson, 1978; Stivers, 2008). Furthermore, the story preface often projects the teller's stance to the events that will be reported, for example whether the story is going to be funny or horrible. The stance is conveyed by the teller and supported by the recipient (for example through nodding, facial expression, and minimal verbal affiliation) during the telling phase, and finally fully responded by the recipient in the story completion. The preferred response to the story mirrors the affective stance that the teller conveyed (Stivers, 2008; Jefferson, 1978; Sacks, 1974; Ruusuvuori and Peräkylä, 2009; Peräkylä and Ruusuvuori, 2012; Couper-Kuhlen, 2012; Selting, 2010; Kupetz, 2014).

Despite these recurrent structural features of storytelling, stories in spoken interaction are not necessarily simple and straightforward in the delivery and reception of affective stance. The affective stance in a story can be also vacillating, twofold or ambiguous. In prior interactional research, ambivalence in stories has received only little attention. In their study on facial expressions, Ruusuvuori and Peräkylä (2009: 386-392) discuss a case of storytelling where the teller conveys both troublesome and humorous stance toward a single topic. Ruusuvuori and Peräkylä showed how the teller of this particular story (about sewer bugs) used both verbal means and facial expressions to alert the recipient to slight changes of stance during the course of telling the story, and how there was some pursuit (by a subsequent assessment and an increment to the assessment and by qualifying facial expressions) from the part of the teller before both the stances were eventually reciprocated by the recipient. Hakulinen and Sorjonen (2012) discuss recipient's management of an ambivalent stance through a Finnish response cry "voi että" (combination of two particles). They suggest that this combination of particles allows the recipient of an emotionally ambivalent turn to respond with an affective expression but at the same leave unspecified what kind of affect is in question.

In this paper, our main argument considers this kind of ambivalent stance. We conducted a quasi-experimental study in which the participants were asked to talk about happy events and losses in their life. Our initial research question was how the happy or sad affective stance that is displayed in storytelling connects to physiological activation in the participants. Physiological indicators of emotional valence (facial muscle activation) and arousal (autonomic nervous system activation) were measured during the conversations. In qualitative exploration of the videotaped conversations, it turned out that despite the instruction to talk about happy events and losses, the participants often displayed an ambivalent stance toward the events they were talking about. We thus added a category of ambivalent stories to our coding of story valence. Through a quantitative analysis of physiological arousal in the participants during stories with different affective stances, we will show how ambivalent stance that is displayed by the teller associates to physiological arousal in the recipient in ways which, to our understanding, might reflect the recipient's interactional task of stance mirroring.

\subsection{Studying linkages between interaction and physiological emotion process}

Earlier interaction research - especially in conversation analysis - has been based on the premise that interaction has its own organization and regularities that can be empirically described without tracing them back to physiology or psychology of the participants (Goffman, 1983; Sacks et al., 1974; Schegloff, 2007); and that also emotional displays are finely interactionally regulated, as they are bound to the sequential organization of interaction (e.g. Jefferson, 1984; Goodwin and Goodwin, 2000; Maynard, 2003). Recent CA research has begun to show that this is the case regarding not only talk (and its prosody) but also bodily displays of emotion: posture, gesture and face. Such emotional expressions as smile and frown have been shown to be - rather than spontaneous expressions of the single individual's emotional state interactionally organized and regulated. In other words, they appear in specific places in interaction and they have interactional consequences (Goodwin et al., 2012; Ruusuvuori and Peräkylä, 2009; Kaukomaa et al., 2013; Peräkylä, 2012). This conception of emotion in interaction motivates also the current study. We will, however, also deviate from the working hypothesis of the 'autonomy' of the organization of interaction, by investigating the linkages between the sequentially organized interactional events and the physiological responses in the participants.

Physiological responses are not socially available for observation in the same way as words, facial expressions or gestures are (even though, arguably, they are part of the interactants' subjective experience, because we also feel our 
bodily reactions). Therefore, using interactional data, it is not possible to demonstrate their relevance for participants in the same way as we can demonstrate the relevance of, for example, falling intonation as a cue for turn transition. However, we hypothesize that the physiological responses are linked to the organization of the observable events in interaction. In this investigation, we draw from Beebe and Lachmann (2002) who suggest that interactional regulation of emotion and the participants' self-regulation of emotion are systemically linked. According to this theory, means that participants use in regulating each other's emotion expression in the interaction are simultaneously means of regulating their felt emotion and the physiological processes pertaining to that. In other words, up or down regulating the subject's or his/her cointeractant's emotional expression in interaction would be simultaneously reflected in the bodies of the participants. A close connection between interactional processes and physiological-emotional responses has been suggested also in terms of emotional contagion: the human tendency to catch and experience the emotions of others has been explained as the result of behavioral mimicry of the co-participants emotional expressions (Hatfield et al., 1993). In this model, physiological-emotional responses in an individual are thus produced through social interaction.

Our interest is to empirically study the possible systemic linkages between the social and the physiological facets of emotion. The current paper reports the first results in this research project, showing a linkage between the affective stance in storytelling and physiological activity in the participants.

In this study, we follow the prevalent psychological view that breaks down affective phenomena - i.e. affective stimuli as well as emotional experience - into two key dimensions: valence and arousal (Larsen and Diener, 1992; Barrett and Russel, 2009). Valence refers to the hedonistic tone of the emotion, i.e. whether it is pleasant (positive) or unpleasant (negative). Arousal, on the other hand, refers to the bodily activation associated with an emotional experience. Positive or negative emotions can involve either a strong or weak arousal component. In theoretical models, based on how research subjects evaluate and group emotion concepts, different emotions have been portrayed in such two-dimensional valencearousal space. In this space, happiness and sadness, for instance, both involve fairly moderate values on arousal dimension, but differ considerably on valence dimension, since happiness is a pleasant feeling, and sadness an unpleasant one (Russell, 1980; Toivonen et al., 2012).

In psychophysiology and cognitive neuroscience, the valence and arousal dimensions of emotion have been shown to be anchored in different organizations of the human body. The activation of the facial muscles in the brow, cheek, and periocular muscle regions is linked to the valence of the emotion (Bradley and Lang, 2007: 590-592); it is these activations that we measure in the study at hand. Importantly, facial muscle activations appear also in the absence of overt facial expression, and therefore, they can indicate both overt and "covert" emotional processes (Larsen et al., 2008). In other words, the facial expression (smile and frown) - that is part of interactional regulation of emotion - and the activation of the facial muscles are thus largely overlapping but also partly different phenomena. The arousal component, then, involves the activation of the autonomic nervous system, detectible for example in heart rate, electrodermal activity (EDA), and frequency of breathing (Bradley and Lang, 2007: 587-590). Besides heart rate, a common measure in the study of physiological arousal is electrodermal activity, commonly known as skin conductance. As people experience arousal their sympathetic nervous system (i.e., the other branch of the autonomic nervous system) is activated, resulting in increased sweat gland activity and skin conductance. Electrodermal activity has been shown to be sensitive to different psychological states and processes, and it is widely used to study attention, information processing, and emotion. In general terms, electrodermal responses are sensitive to stimulus novelty, intensity, and significance (Dawson et al., 2007: 159-160). Electrodermal activity, as well as heart rate, were measured in this study, too. Being controlled by the autonomic nervous system, they are largely beyond the volitional control of the individual.

Psychophysiological studies have sought to specify the autonomic nervous system activation (arousal) associated with specific emotions. Especially anger and fear have been linked to heightened arousal (see Kreibig, 2010; Cacioppo et al., 2000). Also happiness (e.g. Gehricke and Fridlund, 2002) and joy (e.g. Vrana and Gross, 2004) involve increased physiological arousal. The picture regarding sadness is not so clear, as in some studies, it has been linked to an increase (e.g. Levenson et al., 1991) and, in large majority of the studies (Kreibig, 2010), to a decrease (e.g. Averill, 1968) in physiological arousal. It has been suggested that the increased arousal in sadness is associated with crying or combination of sadness with anxiety, whereas sadness without crying or anxiety more likely links to a decrease in arousal (Gross et al., 1994; Rottenberg et al., 2002; Kreibig, 2010). The studies considering the physiological activation in different emotions involve settings that measure response to stimuli with specific emotional content (e.g. film clips) as well as studies that link physiological measurements to self-reported emotional experience (e.g., autobiographical emotional memories; Kreibig, 2010).

To the best of our knowledge, studies on autonomic nervous system activity patterns related to ambivalent emotions have not been reported. Other research relevant for understanding ambivalence includes, for example, theories of emotion in which happiness and sadness are seen as polar oppositions that are mutually exclusive (see Russell and Carroll, 1999). However, Larsen et al. (2001) demonstrated that (in association to emotionally ambivalent film material) people can report feeling happy and sad at the same time. Neuroscientific studies by Viinikainen et al. (2010, 2012) suggest that instead of being poles of a single continuum, brain mechanisms for evaluating stimuli with positive valence 
and brain mechanisms for evaluating stimuli with negative valence are separate, and independent from each other. It seems also possible that these two processes can be activated simultaneously (Viinikainen et al., 2012). However, it has not been persuasively demonstrated that ambivalence consists of simultaneous emotional feelings or rapid switching between feelings.

While most previous psychophysiological research has focused on physiological responses of individual subjects to different affective stimuli in strictly-controlled experimental settings, some earlier studies have taken natural social interaction into focus. In a very early study on psychotherapeutic interaction, DiMascio et al. (1957) showed correlations between features of the patient's talk, coded with Bales' (1950) Interaction Process Analysis categories, and the participants' heart rate. The category of "showing tension" in the patient's talk was associated with increased heart rate of both participants, and the category of "tension release", on the other hand, was associated with a decrease in heart rate in the patient. In their well-known work, Levenson and Gottman (1983) showed synchrony in psychophysiological activation of married couples (in a combined measure of heart rate, skin conductance and movement), which was higher during an emotionally intensive discussion on their marital problems compared to neutral topics. In further studies on psychotherapy, emotionally dense interactions (identified by lexical analysis) were linked to increased variation in physiological responses (Villmann et al., 2008), and therapist empathy, as it was perceived by the patient, was linked to increased synchrony in skin conductance of the participants (Marci et al., 2007). Team performance is yet another setting for earlier interactional studies on psychophysiology. Better team performance has been linked to both increased variation (Elkins et al., 2009), as well as synchrony (Henning et al., 2001), in physiological activation in team participants. Furthermore, in a recent study, Feldman et al. (2011) demonstrated synchrony in heart rate during segments of mutual play between mothers and their babies.

Taken together, these studies suggest that inter-connections between interactional and physiological processes can be found, at least during emotionally or otherwise intense moments of interaction (Hatfield et al., 1993). In the previous studies, different coding systems, self-reports, and outcome measures were used to study the quality of interaction. To the best of our knowledge, our study is the first one that links psychophysiological measurement to concepts and methods drawn from conversation analysis.

In the current study, we wanted to study physiological responses in participants during storytelling episodes. Our interest in stories was based on the earlier interactional research showing that storytelling is a recurrent locus for sequentially organized, reciprocal displays of affective stance (Jefferson, 1978; Stivers, 2008; Selting, 2010). Drawing from this line of research, as well as from the systemic theory of emotion regulation (Beebe and Lachmann, 2002), and the research on autonomic nervous system activation in happiness and sadness referred to above (see Kreibig, 2010), we hypothesized that the valences of story stances (happy, sad and ambivalent) would be differentiated by autonomic nervous system activation and facial muscle activation in both participants during the storytelling. In terms of autonomic nervous system response (indicative of arousal) we expected that the happy stories would be associated with higher heart rate and stronger electrodermal activation (skin conductance) in both participants, as compared to the sad stories, and that heart rate and electrodermal activation in both participants during ambivalent stories would fall between what would be observed in happy and sad stories. Regarding the facial muscle activation known to be associated with facial expressions (smile and frown) and the valence of emotion, we expected that the happy stories would elicit more EMG activity associated with smiling and positive emotions (measured by the activity of the orbicularis oculi muscle, EMG-OO), and sad stories would elicit more EMG activity associated with frowning and negative emotions (activity of corrugator supercilii, EMG-CS) in both participants. Furthermore, we expected that activation of facial muscles in the ambivalent stories would fall between what will be observed in happy and sad stories.

\section{Data and methods}

\subsection{Data}

The data consist of 20 recordings of $45-60$ min dyadic conversations. The participants were female university and polytechnic students who were recruited to this study and did not know each other beforehand. The mean age of the participants was 23.5 years, ranging from 18 to 46 years. The participants were instructed to talk about happy events and losses in their life in a freely chosen way. They were informed that the study considers connections between interactional events and psychophysiological responses, and they were given the topical instruction (to discuss happy events and losses) before the actual discussion took place. They also filled questionnaires before and after the conversation (the questionnaire information is not used in the current study). Informed consent was obtained. From the original corpus (21 recordings), one recording was omitted from this study because the other participant had brought with her written notes about what she was going to talk about and was using these during the conversation. This affected the interactional dynamics and we discarded the data. 


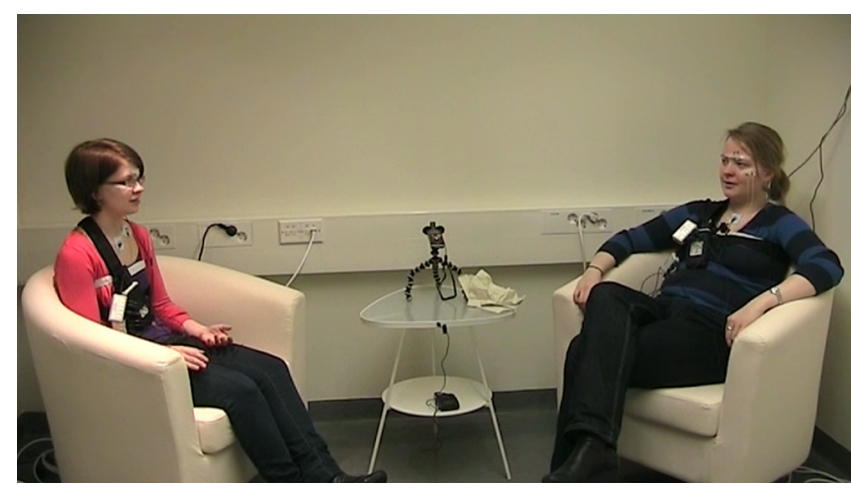

Image 1. The research setting.

The conversations took place in an acoustically shielded room where the participants sat in armchairs facing each other perpendicularly. The conversation was videotaped with three cameras. During the conversations, psychophysiological activity was measured with two Varioport-B portable amplifiers (Becker Meditec, Karlsruhe, Germany) and recorded to a memory card. Data from both members of a dyad were synchronized with manual markers before and after the experiment. Image 1 shows the research setting. (We have got permission from the participants of this dyad for the publication of still images from the conversation).

ECG signal was recorded with $512-\mathrm{Hz}$ sampling rate using wet electrodes placed according to Lead 2 alternative placement guidelines (Berntson et al., 2007). R-peaks of the heartbeats were detected, corrected for ectopic beats and 4- $\mathrm{Hz} \mathrm{HR}$ (beats per minute) series was formed by interpolating the series of heartbeat intervals with cubic splines using the ECGlab software (De Carvalho et al., 2002).

Electodermal activity (EDA) was sampled at $32 \mathrm{~Hz}$ with a constant voltage of $0.5 \mathrm{~V}$ with wet $\mathrm{Ag} / \mathrm{AgCl}$ electrodes placed on the palmar middle phalanges of index and middle fingers of the non-dominant hand. Signal was smoothed with adaptive Gaussian filter, separated into tonic and phasic components and downsampled to a 4-Hz series using the Ledalab toolbox (Benedek and Kaernbach, 2010).

Facial EMG signals were sampled at $1024 \mathrm{~Hz}$ at the sites of corrugator supercilii (CS) and orbicularis oculi (OO) muscles per guidelines of Fridlund and Cacioppo (1986). Signals were bandpass filtered $(57-390 \mathrm{~Hz})$ by analog filter of the Varioport device, with an additional notch filter at $50 \mathrm{~Hz}$. Signals were rectified, smoothed with a 100-ms moving average filter, and integrated into a 4-Hz RMS value series.

\subsection{Coding the stories}

From the video data, all the storytelling instances were coded. Our coding scheme was broadly based on CA understanding of storytelling and affiliation. Two CA researchers (Voutilainen and Peräkylä) of the project built the coding scheme in joint meetings for data analysis. The scheme included coding of the event of storytelling (time code for the onset and the completion of the storytelling event); time codes for the three consecutive story phases (buildup, climax, and possible evaluation); roles of the participants (teller/recipient); and the valence of the affective stance expressed by the teller (happy/sad/ambivalent). As climax phase was coded the time from the beginning of the turn unit where the punchline of the story was delivered until the end of the recipient's response turn to the climax. The phase before the climax was coded as build up. After the initial response to the climax, possible further evaluation that was closely related to the story was coded as the evaluation phase.

We also built a scheme for coding the reception of the story regarding verbal and nonverbal affiliation. In this paper we will focus on the valence of the stance, so the coding of affiliation is not used in the current study.

Our comprehension of storytelling was inclusive: besides long and complex narratives, also relatively short tellings that described some kind of progress of events in time were coded as stories. As to be expected, coding was not without challenges. There were cases in which it was difficult to the coders to decide whether a telling is a story or whether it is some other type of topic talk; let alone the start and end points of the story and story phases. Especially in cases where a story continued with another story it was difficult to distinguish between the borders of the stories. We however reached a satisfactory level of inter-coder reliability that is reported below.

In many cases the valence of the story - i.e., the stance of the teller - was clearly evident in reference to the words in the instruction (happy events and losses) or in other emotional or evaluative words that obviously refer to positive, negative or contradictive stance toward the events that are told. In some cases, however, the coders had to rely more on their "members' knowledge" on what is taken as happy, sad or ironic in the common (Western) culture. 
The instruction to talk about happy events and losses obviously produced stories with either positive or negative valence. These were named as classes of "happy stories" and "sad stories". When building the coding scheme we soon noticed that we need a third class of valence, namely ambivalence. As ambivalent, we coded stories that involve two different stances toward the events that were told, basically a positive and a negative stance. These included stories with verbal expressions of mixed or ambiguous feelings toward the events in question, as well as stories in which the mode of the telling had a different valence than the content of the story as such. The latter type ambivalent stories were basically stories about troubles that were told in a humorous or ironical manner (such as the story about sewed bugs in Ruusuvuori and Peräkylä, 2009). In these stories, the tellers displayed through lexical and prosodic means that their stance is not fully serious even through the events as such were not positive. It is important to note that stories exhibiting troubles resistance (in the sense of Jefferson, 1980: the teller of untoward events producing positive affect displays which are not ironical or comic, but rather show her perseverance) were not included to the class of ambivalent stories but were coded as sad stories. In stories that were coded as ambivalent there was a more salient tension between the comic and the tragic than in the cases of troubles resistance. As a special case, our coding scheme for ambivalence included also stories about worrying situations that ended up fine (6 cases in the data). Stories that were not offered as personally happy, sad or ambivalent were coded as "other stories" and were not included to the analysis.

It should be emphasized that our coding of the valence of the story is based on the teller's stance displays, not on how the recipient treated the story. This is a key part of the research design, as the task of this study is to find out how the recipients, through their physiological responses, respond to stories that are designed to convey different emotional valences. One could even say that in this study, the physiological response as it were occupies the place of the "second position" action that reveals the recipient's understanding of the first position action (in this case, the story). As will be shown below, the recipients, through their physiological responses, indeed do treat differently the happy, sad and ambivalent stories.

The story recipients' interactional displays remain, of course, equally important. Our analysis of the physiological ramifications of the story recipients' affiliation displays will be reported elsewhere (Peräkylä et al., submitted).

Three authors (Voutilainen, Kahri and Peräkylä) participated in the coding. 35\% (7/20) of the discussions were randomly selected and double-coded to assess the reliability of the coding system. The coded stories were converted into one second segments, to which values were assigned according to speaker, story valence and story phase. Weighted kappa coefficient (Cohen, 1968) was calculated for each double coded discussion. The codes were linearly weighted so that disagreement in phase was calculated as $33 \%$ error whereas disagreement in both phase and valence was calculated as $66 \%$ error. Mean kappa value was $0.55(0.50-0.67, S D=0.05)$, which indicates moderate agreement according to Landis and Koch (1977). Attained kappa value is influenced by prevalence effect in the data, making large kappa scores harder to attain (Sim and Wright, 2005). The prevalence effect was calculated as the mean ratio of most prevalent code (neutral) instances to other code instances. This method yielded an index of 0.85 . Correcting the kappa values for prevalence effect produced a kappa score of 0.67 . In the set of double coded conversations, the second coder found $81 \%$ of the stories accurately. In $24 \%$ of the agreed-upon stories, the second coder's assessment of valence differed from that of the first coder. $53 \%$ of the differing valences were cases of "other" stories coded as valence-laden and vice versa. $47 \%$ of the cases were ambivalent stories coded as having happy or sad valence and vice versa. None of the stories with happy valences were coded as sad by the second coder and vice versa.

\subsection{Happy, sad and ambivalent stories: Examples}

To illustrate the data and the interactional events that were studied, we present examples of the story types. The first example shows a case of a happy story.

Example 1: Happy story

01 B: [Et me Kroatiassa hypättii semmoselta: (0.4) mt .hhh

[So in Croatia we dived from one of tho:se (0.4) mt .hhh

$02 \mathrm{~A}:[\mathrm{Mm}: \underline{\mathrm{m}}$,

03 B: semmoselta< tai niinku: (0.2) kun siel on semmoset

one of those< or like (0.2) as they have 
04 niide mhhh \#ää\# kallio: rannat tai silleen.=semmoselta those mhhh \#ää\# rocky shores or such like.=so from one of

05 kalliosta ^mereen nii se \#o:\# siis mä muistan a:ina

those cliffs into the ^sea so that \#wa:s\# like I will a:lways

06 sen.

remember that.

$07=$ se oli niin siisti tai ^sillee. .hhh se oli kyl

it was so cool or like. .hhh it was really

08 aika sem'ne ^ilonen (0.2) myös.

a quite sort of joyful (0.2) too.

09 A: Öö: : (.) millä te hyppäsitte s[i(n)

Erm:: (.) what did you dive with th[e(n)

10 B :

$$
\begin{aligned}
& \text { [Siis (.) me hypättii } \\
& \text { [So (.) we dived }
\end{aligned}
$$

11

vaan niinku kalliosta.=(kts)(kato)(.) sku se oli

just like from the cliffs.=(see) (you see) (.) because that was

12

ihan siinä rannalla (siellä [ihan<)]

right there on the beach (there [just<)]

$13 \mathrm{~A}:$

$$
\begin{aligned}
& \text { [Joo: ]o, } \\
& \text { [Yea]h, }
\end{aligned}
$$

14 B: nii sieltä me hypättii vaa niinku< (.) näin sil (•) so we just dived from there like< (.) like this (.)

15 tousi korkeelta ni se<

from really high so that< 
. hhh mä muista[n aina sen siis sille]e, .hhhh

.hhh I'Il always re[member that [.hhhh

$18 \mathrm{~A}:$

[ Eh:: heh heh he:]

19 B : jote $[\mathrm{nkin}$.

some [how.

20 A: [Voi luoja. (0.4) ^okei. (0.2) Hh $\mathrm{h} \mathrm{h} \mathrm{h}$ [Oh my God. (0.4) ^okay. (0.2) Hh h h h

\section{--- EVALUATION PHASE STARTS ---}

21 B: Tse on vaa (>nii jotenkii<) silleen et se on niinku< It's just (>somehow<) like it's just

$22 \mathrm{mh}(0.2)$ jotenki nii:n semmone voimakas kokemus $\mathrm{mh}(0.2)$ somehow such a powerful experience

23 vaikka ei se siis sillee .mhhh jos mä hyppäisi even though it's not really . mhhh if I dived

24 (>js<) uimahallis nii ei se nyt ois nii siistii- mikä jäis (>like<) at a swimming hall it wouldn't be so neat-sticking

25 mielee mutta,

in mind but,

26 A: Mä en tajuu miten sä uskal[sit oikeestí. ]

I don't get it how you da[red really. ]

27 B :

[Eh he heh he he] .hhhhh

$28 \mathrm{~A}$ : ^No joo, (0.4) s[iit jäi hyvät mui[stot sitte.]

${ }^{\wedge}$ Well yeah (0.4) that left a good m[emory then ]

29 B :

$[\mathrm{Mm}$ :

[ $\hat{m m}:, \quad]$

30 B: Niinpä.

Quite right.

$31 \mathrm{~A}:{ }^{\wedge} \mathrm{Mm}:$, 
In this example, the teller (B) displays a salient positive stance toward the event that she talks about (jumping from a rocky shore into the sea in Croatia). She describes this experience as "so cool" and "sort of joyful too" (here the joyful, iloinen, presumably refers to the instruction in which the same Finnish word was used), and, after a question-answer sequence in lines 9-13, she continues to evaluate this experience as something that she will always remember and as "somehow such a powerful experience". Also the prosodic mode of the telling could be characterized as "enthusiastic" (see e.g. stress in always, aina, in line 5 and stress in the intensifier nii in line 7). In this example, the stance displays by the teller are thus rather strong. It is worth noticing, however, that our collection of happy stories involves a lot of variation in the strength of the displays of stance by the teller.

The next example shows a sad story.

Example 2: Sad story

$01 \mathrm{~A}:$ Mulla kans to\#ta:\# (0.2) mun (.) täti kuoli tossa

For me too \#erm\# (0.2) my (.) aunt died

02

m- (0.4) vähä yli vuos sitte, h .hhh

m- (0.4) a bit over a year ago, $h . h h h$

$03 \mathrm{~B}: * \mathrm{~m}: \underline{\mathrm{mh}}$ *

04 A: kuuskymppisenä syö^pään elikkä ei mikää kauh^een (0.2) vanha

in the age of sixty of $\operatorname{can}^{\wedge}$ cer so not a $v^{\wedge}$ ery (0.2) old

05 ihminen?

person?

06 B: Niih,

Yeah,

$07 \quad(1.5)$

08 A: Nii se: (1.0) edelleenki niin (2.0)

So that (1.0) still like (2.0)

--- CLIMAX PHASE STARTS ---

09 A: ^välillä se unohtuu ihan täysin ja sit välillä se iskee

every now and then one forgets it completely and then again it strikes

10

taas hurjasti et ei o[o tavallaa mitää semmost puolitietä,=

back again strongly so in a way there's no middle ground,=

11 B : 


$$
\begin{aligned}
& 12 \text { B : =Niih, } \\
& \text { =Yeah, }
\end{aligned}
$$

--- EVALUATION PHASE STARTS ---

13 A: siinä et mä oon se< m- mä reagoin niinku näihin asioihin there so that $I^{\prime} m$ the< I- I react to these matters

$$
\text { sillä tavalla, }
$$$$
\text { in that way, }
$$

$$
(2.5)
$$

$16 \mathrm{~A}:$ ja se \#h\# hhh jotenki tollaset hhhhhhh (0.2) ne on and it's \#h\# somehow such things hhhhhhh (0.2) I think they are just so pointless deaths but what [can I

19 A: nille voin.

do.

This story is offered as a second story in a response to a story about a loss. While telling about the death of her aunt, A offers an evaluation on the age of deceased, and, after an affiliating minimal response by the recipient, displays her current relation to this loss, which she summarizes by stating that "in a way there is no middle ground" (between completely forgetting it and strong reactions) (lines 1-10). After an affiliating minimal response, the teller continues to reflect her reactions, and finally states that "I think they are just so pointless deaths but what can I do" (lines 13-19). The overall prosodic mode of the telling is in line with the serious content of the story. In this case the sad story was about a severe loss, but in the collection we have also stories about less tragic events. Like in the happy stories collection, also the sad stories collection involves lot of variation in the strength of the stance displays.

The Example 3 below shows a case of a story in which the stance by the teller is ambivalent. Before the extract, A has told that her son has recently moved away from home, to begin his studies in a university. She has pointed out that this could be seen as a loss, but that actually she thinks that it is part of life and how things must go. The co-participant has received this line of thought by suggesting that this situation is nevertheless some kind of a crisis or a development task to the mother. A has agreed with this but indicated that she does not take this change as emotionally as somebody else might do. Then she seems to be moving toward expressing the sad side of the situation by changing her tone of voice and saying kyllhän se oli (something like "yes you know it was") and starts to tell about the high school graduation party of her son. This telling involves an ambivalent story.

Example 3: Ambivalent story

1 A: niinku (.) .hhh

$$
\text { like (.) .hhh }
$$

$$
\begin{aligned}
& \text { (.) meil oli ne lakkiaiset mikä oli niinku } \\
& \text { (.) we had the graduation ceremony which was like }
\end{aligned}
$$


3 y:- (.) >tämmöne< ila- (.) iloinen tapahtuma

y:- (.) >one of these< hap- (.) happy events

4 \#tosi hyvin kirjotti viel poika ni\# (0.4) . mth

\#the lad got so good marks as well so\# (0.4) .tsk

5 (0.2) ö- (.) viis ällää (0.2) tai e:tä \#kirjotti

(0.2) ö-(.) five times laudatur (0.2) or eximia the got

6 niinku\# (.) \#niil oli lakkiaiset ni oli tosi kiva

like(.)so they had the graduation ceremony so it was very nice\#

$7 \quad(0.2) 0-$,

(0.2) i-,

$8 \quad \mathrm{~B}: \mathrm{j}[\mathrm{OO}$.

$y[e a h$.

9 A: [\#oli kaunis päivä ja\# (.) m- ol[i vieraita

[\#it was a beautiful day and\# (.) there [were guests

10 B :

$[\mathrm{mmm}-\mathrm{m}$.

$11 \mathrm{~A}:$ ja .hhhh (.) eli tse oli niinku sillee \#kivah\#

and.hhhh (.) so it was like \#nice h\#

12 (.) ja sitte (0.6) tiesi kuiten[ki et sil (.)

(.) and then (0.6) I knew on [the other hand that he (.)

13 B :

[nii.

14 A: >oli niinku< lähössä opiskelee muualle (0.2)

>was like< leaving (home) to study (0.2)

15 ni (0.2) sitte (0.2) tavallaan (0.4) se juhlaki

so (0.2) then $(0.2)$ kind of $(0.4)$ the party too 
16 oli just sillee niinku että (.) nyt se sit

was just somehow like (.) now he's just going to

17

menee tosta että,

leave so,

18

$$
(0.2)
$$

19 B : n[ii.

20 A: [sen niinku ties tavallaan,

[ I was already aware of it somehow,

21

$(0.4)$

22 B: ${ }^{\circ}$. $\left[i i^{\circ}\right.$.

--- EVALUATION PHASE STARTS ---

23 A: [et oli ilonen mut sit \#samalla niinku\# (0.4)

[so I was happy but then \#at the same time like\# (0.4)

24 tiesi et se ${ }^{\circ}$ on nyt sitte ${ }^{\circ}$.

I was aware that just about now ${ }^{\circ}$ he' $s^{\circ}$.

25

$$
(0.2)
$$

$26 \mathrm{~B}: \mathrm{mmm}-\mathrm{m}_{\mathbf{0}}=$

$27 \mathrm{~A}:={ }^{\circ}(1 \text { ähteny jo })^{\circ}$,

${ }^{\circ}(\text { gone already })^{\circ}$

28

$(0.4)$

29 B : n[iih.

30 A: $\quad[\#>$ muualle< opiskelemaan\#.

[\#>elsewhere< to study\#.

$31 \quad(0.4)$

32 B: nii-ih? 
34 A: .mts .hhh (.) et silläki on niinku tyttöystävä

.tsk .hhh (.) 'since he has like a girlfriend

35

\#silleen että\# (0.2) asu:vat jo yhessä ja \#näin

\#so that\# (0.2) they live together already and \#so on

36

et >se oli ihan< selvää että ne [muuttaa\#

so >it was quite< clear that they'd be [moving\#

37 B :

[ joo.

[yeah.

38 A: siitä sit yhteen ku koulu on ${ }^{\circ}$ hoidet.tu: ${ }^{\circ} \cdot=$ to a place of their own once they were done with ${ }^{\circ} \mathrm{sch} .001^{\circ} .=$

39 B: nili-i (0.2) okei?

right (0.2) okay?

40

$(\cdot)$

41 A: mmm-m.

$$
(0.2)
$$

43 B: ${ }^{\circ}$ joo-oh. ${ }^{\circ}$

- yea -ah. ${ }^{\circ}$

$$
(3.0)
$$

In this story, the teller (A) tells about mixed feelings in her son's graduation party. She first describes the happy side of her experience by telling about her son's excellent grades, and about the nice party (lines 1-11). From line 12 she moves to the sad side of the experience by telling about her awareness about that her son is leaving home. When moving to the sad side of experience in line 12, the teller makes a horizontal hand movement which can be seen as communicating the shift of valence. After a minimal response by the recipient (line 19), the teller continues by summarizing the ambivalence of happy and sad feelings in lines 23-24 and after a minimal response (line 26), by expanding her turn in lines 27 and 30 , and after again minimal response (line 32), finally by producing an evaluation which mitigates the ambivalent experience that she was describing by pointing out that the son's moving from home was really expectable (lines 34-38). The recipient again responds minimally (line 39), and the storytelling sequence closes. The teller also slightly changes her tone of voice according to the changes in the valence of the telling.

Stories with displays of mixed feelings toward the events in question are common in our collection of ambivalent stories. In extract 3 above, the two stances were as it were balanced as the teller offered them as more or less equal "sides of the coin". In the collection, there is variation in how the relation between the two stances is displayed: the positive and negative side can be offered as equal, or one stance can be offered as more primary or strong than the other. There is variation also in whether the conflict between the two kinds of emotions is offered as problematic. Our coding, however, did not distinguish between these different weightings of the stances. As was reported above in terms of inter-coder reliability, in cases where one stance was much stronger than the other the coders sometimes decided differently between the categories of ambivalence and solely happy or sad.

Besides verbal displays of mixed feelings, ambivalent stance can involve a mixture of comic and tragic. The Example 4 below shows an example of this kind of ambivalence. Before the extract the teller has told about a chain saw accident that 
happened to her father. This story has been told as a serious, sad story. In the beginning of the extract the teller starts to tell about an aspect in the accident that she offers as somewhat comic. This later telling, starting in the beginning of the extract, involves an ambivalent story.

Example 4: Ambivalent story

1 A: seki on jännä ku se ei ollu sitä aluks ees niinku another thing that's curious is that at first he hadn't even

6 A : ju[st (.) jollai (.) . .hhh=

jus [t (.) with some (.) .hhh=

7 B : $\quad[$ hhhh

8 B : = $\uparrow$ he $[\mathrm{h}$ he

9 A: [siis (0.2) phhhh heh .hhh (.) niinku oli ollu [like(0.2) phhhh heh.hhh (.) like there had been

13 A: niinku (0.4) <hưuhdell[u> tai (.) p[uhdist (h) an (h)u like (0.4) <rins[ed it out with> or (.) cl[(h)eans(h)ed

15 A: s:i(h)tä(h) ja(h) si[t ku >ne oli alkanu< m:ärkii it $w(h)$ ith and(h) th[en when >they had began to< $f: e s t e r$ 
17 A: ni sit se oli vast niinku älynny lähtee lääk äo.riin so only then had he come up with the idea to go to see a doctor

18 $\cdot \operatorname{thh} \cdot \mathrm{mts}=$

19 B : =kiva.

$=n i c e$.

(.)

--- CLIMAX PHASE STARTS ---

19 A: vähä (.) m[ahoton.

(he's) a bit (.) im[possible.

20 B : $\left[\mathrm{mm}^{\circ}()^{\circ} \mathrm{lla}\right.$ on $\mathrm{kyl}$ varmaan katott [mm at ${ }^{\circ}()^{\circ}$ they must have looked at him

21 vähän et (.) 个m:[:: : (.) oi[s pitäny tulla heti.

like (.) Tm: [:: (.) (you) should have come right away.

22 A:

$$
\begin{array}{ll}
\text { [.hhh } & \text { [ joo. } \\
{[\cdot h h h} & \text { [yeah. }
\end{array}
$$

23

(.)

$24 \mathrm{~A}: \mathrm{m}[\mathrm{hh}$

25 B : [.mts (.) ․voi .että․

$$
\left[\cdot \operatorname{tsk}(\cdot)^{\circ} \cdot \text { oh }_{\text {.dear }}^{\circ}\right. \text {. }
$$

$26 \quad(0.2)$

27 A: m[ut e::i (.) ku se ajatteli (.) no ei ku ei se tuntunu b[ut no: : (.) he thought that (.) well it didn't feel

$28 \mathrm{~B}: \quad[\mathrm{hm}$.

29 A: sillee kipeeltä(h) h[hh too sore $(h) \quad h[h h$

30 B :

[ $\underline{m m m}[\mathrm{~m}$,

$31 \mathrm{~A}$ : [.mts äh he .h[hh (.) hhh=

32 B : [hm 
33 в: =luulis kyl et tulntuis eh.

=you'd think that it [would feel eh.

34 A :

$$
\begin{aligned}
& \text { [ no joo me mi- einasin just et se } \\
& \text { [well yeah m- I- meant that it }
\end{aligned}
$$

35

tuntu mut (.) on [neks se ei ollu kuitenkaan sillee

felt but (.) luckily it hadn't like

36 B :

$$
[\mathrm{mm}-\mathrm{m} \text {. }
$$

37 A: menny niinku lihakseen et se oli to[st vetässy

gone to the muscle so that it had j[ust drawn from there

38 B :

[ joo.

[yeah.

39 A: vaan niinku pinnasta et jote $\left[n k i\right.$. sillee ${ }^{\circ}$ mut ${ }^{\circ}$.

from the surface some[how. like obut?.

40 B :

[ joo.

[yeah.

41 ?: .mts

.tsk

42

$(0.6)$

43 B: .mts (.) joo-o.

.tsk (.) yea-h.

44

$(\cdot)$

In lines 1-5 the teller tells about how her father did not go to doctor right away after the accident. Her prosody during this telling is somehow marked, taking distance to the tragedy side and drawing attention to the silliness of her father's reasoning. In line 4 she animates her father's line of reasoning after the accident (he's (0.2) like (.) he's going to rest or(h)). The word tai (or) is here produced with laugh particle, offering the father's reasoning as a possibly laughable matter. After the recipient's laughter (line 8), the teller continues by telling that her father cleaned the wound with some vodka, and went to see a doctor only after the wound began to fester. She again marks the telling as comic with prosody and laugh particles. After a (more serious) response by the recipient in line 19, the teller produces an evaluation about the father as "a bit impossible", which explicates and retains the teller's stance that foregrounds the silliness of her father's reasoning. After the recipient's response (note the "voi että" in line 25, discussed by Hakulinen and Sorjonen, 2012), the teller once more animates her father's reasoning with laughter particles (lines 27, 29 and 31). In line 35 the teller moves to a serious mode and tells that fortunately the injury was not very serious. In sum, during what was coded as the buildup and climax phases, the teller retained the somewhat humorous stance toward her father's reasoning and actions while talking about an evidently tragic event.

The examples above illustrated the events that were coded as happy, sad and ambivalent stories. After coding the stories, the physiological data were analyzed in relation to the storytelling codes to find out whether the valence of the 
affective stance contributes to the physiological activation in the participants. The methods of this analysis are reported below.

\subsection{Data analysis}

Physiological data were analyzed by the Linear Mixed-Models (LMM) procedure in SPSS (version 20.0.1). This method measures whether fixed variables have an effect on the variation of the dependent variable. Unlike the standard analysis of variance, the LMM procedure involves a restricted maximum likelihood estimation, which allows the number of instances (in this case stories) coming from different research subjects to be different.

Separate analyses were conducted for each physiological dependent variable (EMG-OO, EMG-CS, HR, EDA). Story valence (happy/ambivalent/sad), story phase (buildup/climax/evaluation), role (teller/recipient), Story Valence $\times$ Role interaction (i.e., whether the effect of story valence is different in the teller and recipient), and Story Phase $\times$ Role interaction (i.e., whether the effect of story phase is different in the teller and recipient) were specified as fixed effects in the model.

To normalize the distributions, square roots of the original data values were used in the analysis. To take into account that the dyad members and different stories (and phases of stories) from a same person are not independent, participant ID nested within dyad ID was specified as the subject variable and story phase nested within story ID was specified as the repeated variable. Compound symmetry (CS) was specified as the covariance structure for the residuals.

For the significant main and interaction effects, post hoc comparisons of the means of the physiological parameters were conducted. Post hoc significance tests were adjusted with the Bonferroni method, dividing the $p$ value with the number of tests conducted. Confidence intervals for the estimated marginal mean plots were calculated using the method of Cousineau (2005).

\section{Results}

\subsection{Stories in the data}

We found altogether 317 stories from the data. Regarding the valence of the story, 89 stories were coded as happy, 95 stories as sad, 89 stories as ambivalent, and 44 as "other stories". The other stories class includes stories that were not offered as personally happy, sad or ambivalent by the teller and they were not included in the analysis of physiological data. The average length of the stories was approximately $1 \mathrm{~min}$ in all the story types (see Table 1).

In the following section we will report our psychophysiological results from the storytelling instances. We will first compare facial muscle activity (EMG) during the different story types. Then, we will present our main results related to the indicators of physiological arousal (HR and EDA).

\subsection{Indicators of valence: ambivalence sets between happy and sad stance}

As Fig. 1 shows, the stance of the teller was reflected in EMG-OO (orbicularis oculi, associated with smile and positive emotion) activity in the teller and the recipient in the expected way. The mixed model analysis revealed a significant main effect for story valence, $F(2,1444)=159.66, p<.001$; that is, story valence (affective stance) was associated with EMG$\mathrm{OO}$ activity. In the post hoc comparisons of the story types, EMG-OO activity was highest in happy stories $(M=6.98$, $\mathrm{SE}=0.07)$, second highest in ambivalent stories $(M=6.52$, $\mathrm{SE}=0.07)$, and lowest in sad stories $(M=5.53$, $\mathrm{SE}=0.06)$. As Fig. 1 shows, the order between happy, ambivalent and sad stories is similar in the teller and recipient (for all comparisons, $p<.001$, except for happy vs. ambivalent for the recipient, $p<.05$ ).

The mixed model analysis revealed also an interaction effect between story valence and role, $F(2,1443)=4.77$, $p<.01$, meaning that the effect of story type on EMG-OO activity is different for the teller compared to the recipient. A

Table 1

Stories in the data.

\begin{tabular}{lcll}
\hline Type & $N$ & Average length (s) & SD \\
\hline Sad & 95 & 65.73 & 35.37 \\
Ambivalent & 89 & 62.81 & 38.19 \\
Happy & 89 & 53.88 & 27.41 \\
Other & 44 & 48.36 & 29.80 \\
Total & 317 & 59.17 & 33.90 \\
\hline
\end{tabular}




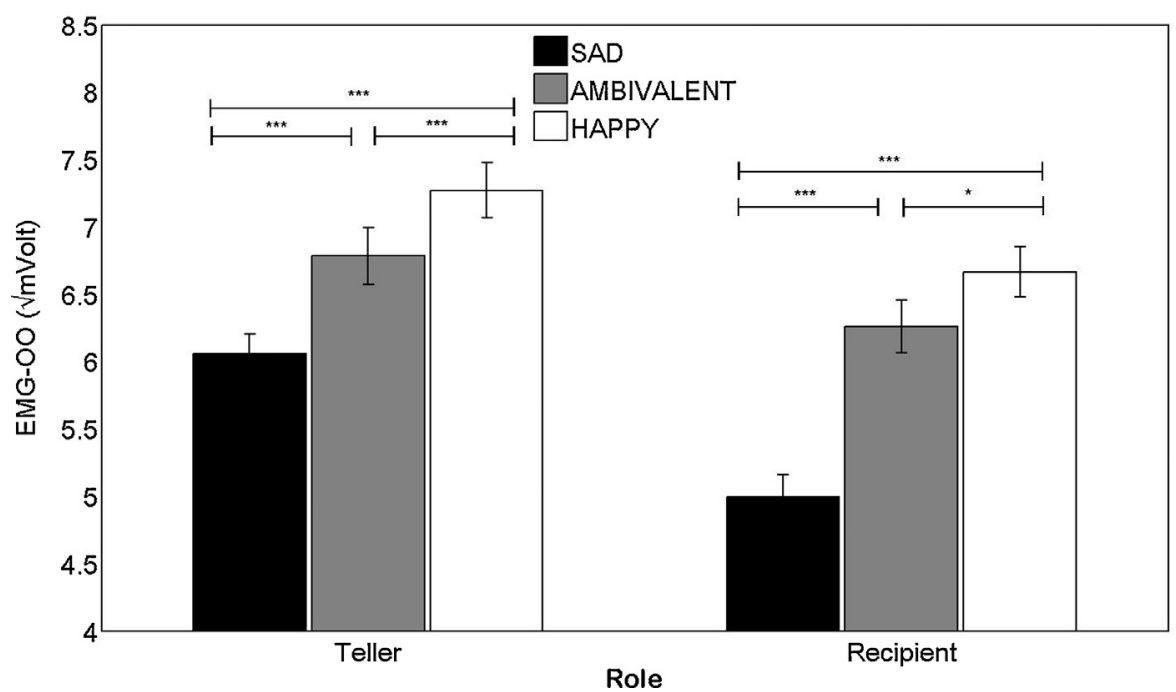

Fig. 1. Estimated means for EMG-OO activity. Error bars indicate $95 \%$ confidence intervals $\left({ }^{* *} p<.001{ }^{*} p<.05\right.$, all values Bonferroni adjusted).

possible explanation for the interaction effect is that the difference between ambivalent and happy stories is not as pronounced in the recipient. The interaction effect can also be interpreted as a more accentuated difference between sad and happy/ambivalent stories in the recipient than in the teller.

A significant main effect was found also for role $(F(1,1443)=103.58, p<.001)$ and for story phase $(F(2,1433)=48.02$, $p<.001)$. Post hoc comparisons show that, in general, EMG-OO activity was higher in the teller $(M=6.68, \mathrm{SE}=0.06)$ than in the recipient $(M=5.92, \mathrm{SE}=0.06)$. Further, smiling activity was, in general, lower in the buildup phase $(M=5.83$, $\mathrm{SE}=0.06)$ than in the climax $(M=6.61, \mathrm{SE}=0.08, p<.001)$ and evaluation phase $(M=6.54$, SE $=0.08, p<.001)$. EMG$\mathrm{OO}$ activity did not differ between the climax and evaluation phases.

Fig. 2 shows that the stance of the teller was reflected also in EMG-CS (corrugator supercilii, associated with frowning and negative emotion) activity of the participants. A significant main effect was found for story valence $(F(2,1455)=37.43$, $p<.001)$. Corrugator activity (teller and recipient combined) was highest for sad stories $(M=3.73, \mathrm{SE}=0.03)$, second highest for ambivalent stories $(M=3.54$, SE $=0.04)$, and lowest for happy stories $(M=3.35$, SE $=0.03)$. The main effect of story valence was qualified by a significant interaction between story valence and role $(F(2,1442)=9.97, p<.001)$ indicating that story valence has a different effect in the teller than in the recipient. For the teller, corrugator activity during

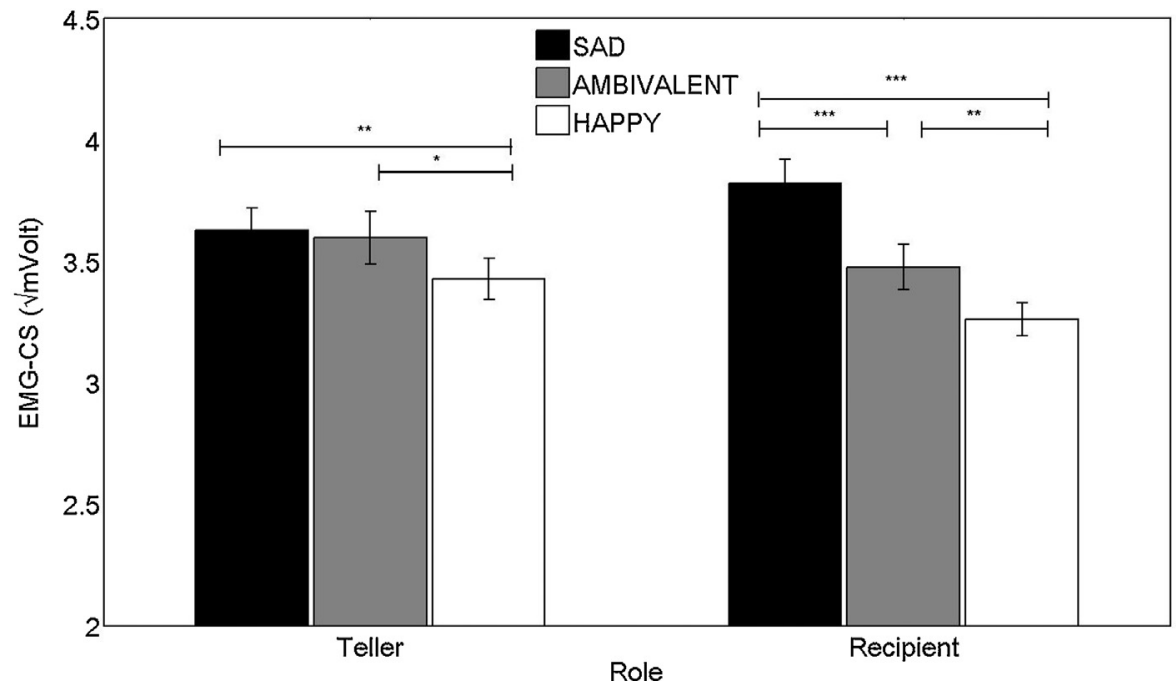

Fig. 2. Estimated means for EMG-CS activity. Error bars indicate $95 \%$ confidence intervals $\left({ }^{* * *} p<.001,{ }^{* *} p<.01\right.$, ${ }^{*} p<.05$, all values Bonferroni adjusted). 
sad and ambivalent stories did not differ significantly. Interestingly, whereas in the other contexts the teller's corrugator activity is higher than the recipient's, in the context of sad stories, the recipient's corrugator activity is higher than the teller's activation (difference $=0.21, \mathrm{SE}=0.07, p<.01$ ).

Other main effects (role, phase) were not significant.

In sum, facial muscle activity during stories with a happy, sad, and ambivalent stance reflected the valence of the affective stance: the story valence and "physiological/emotional valence" were saliently connected, except in the case of comparing the teller's corrugator activity during sad and ambivalent stories. Furthermore, an interesting effect was found from the context of sad stories, as there was more corrugator activity in the recipient than in the teller. This suggests that nonverbal affiliation is perhaps particularly important in the case of responding to a sad story.

Next, we will turn to the results considering indicators of physiological arousal (heart rate and skin conductance) that revealed the specific effect of ambivalent stories in the recipient.

\subsection{Indicators of arousal: ambivalence increases recipient's activation}

As Fig. 3 shows, the relation between story valence and heart rate was partly different in the recipient than in the teller. A significant main effect was found for story valence $(F(2,1436)=16.13, p<.001)$. Activity during the sad stories $(M=8.71, \mathrm{SE}=0.01)$ was lower than in the ambivalent $(M=8.78, \mathrm{SE}=0.01)$ and happy $(M=8.78, \mathrm{SE}=0.01)$ stories (for both post hoc comparisons, $p<.001)$. However, a significant interaction between story valence and role $(F(2,1436)$ $=5.08, p<.01)$ indicated a difference between the teller and the recipient in how story valence relates to heart rate.

As Fig. 3 shows, for the teller, heart rate is higher during happy stories $(M=8.89, \mathrm{SE}=0.02)$ than during sad stories $(M=8.81, \mathrm{SE}=0.02)$. Also for the recipient, activation was higher during happy stories $(M=8.68, \mathrm{SE}=0.02)$ than during sad stories $(M=8.61, \mathrm{SE}=0.01)$. However, in the recipient, heart rate during ambivalent stories $(M=8.72, \mathrm{SE}=0.02)$ was higher than during sad $(p<.001)$ and happy $(p=.056$, trend) stories. Thus, ambivalent stories seem to increase the recipient's (but not the teller's) heart rate.

A significant main effect was found also for role $(F(1,1436)=187.73, p<.001)$. The teller's heart rate $(M=8.85$, $\mathrm{SE}=0.01)$ was higher than the recipient's $(M=8.67, \mathrm{SE}=0.01)$. No significant effect was found for story phase.

As Fig. 4 shows, the other measure of arousal, electrodermal activity (phasic skin conductance) showed a similar pattern of results for the recipient as with HR. A significant main effect was found for story valence in predicting skin conductance $(F(2,1453)=3.20, p<.05)$. Post hoc comparisons showed that skin conductance was lower during sad stories $(M=0.32$, $\mathrm{SE}=0.01)$ compared to ambivalent stories $(M=0.34$, $S E=0.01, p<.05)$. However, the main effect was qualified by a significant interaction between story valence and role $(F(2,1450)=2.99, p=.05)$. As is shown in Fig. 4, for the recipient, ambivalent stories $(M=0.36$, SE $=0.01)$ elicit higher skin conductance than $\operatorname{sad}(M=0.30, \mathrm{SE}=0.01, p<.01)$ and happy $(M=0.30, \mathrm{SE}=0.01, p<.05)$ stories, whereas there were no significant differences between the story stances for the teller.

A significant main effect was found also for role $(F(1,1450)=25.23, p<.001)$. The teller's skin conductance $(M=0.35$, $\mathrm{SE}=0.01)$ was higher than the recipient's $(M=0.31, \mathrm{SE}=0.01)$. No significant effect was found for story phase.

To sum up the main results, the story stances (happy, sad or ambivalent) were differentiated by physiological activity of the participants. In terms of facial muscle activity, the results were as expected: happy stories were most strongly

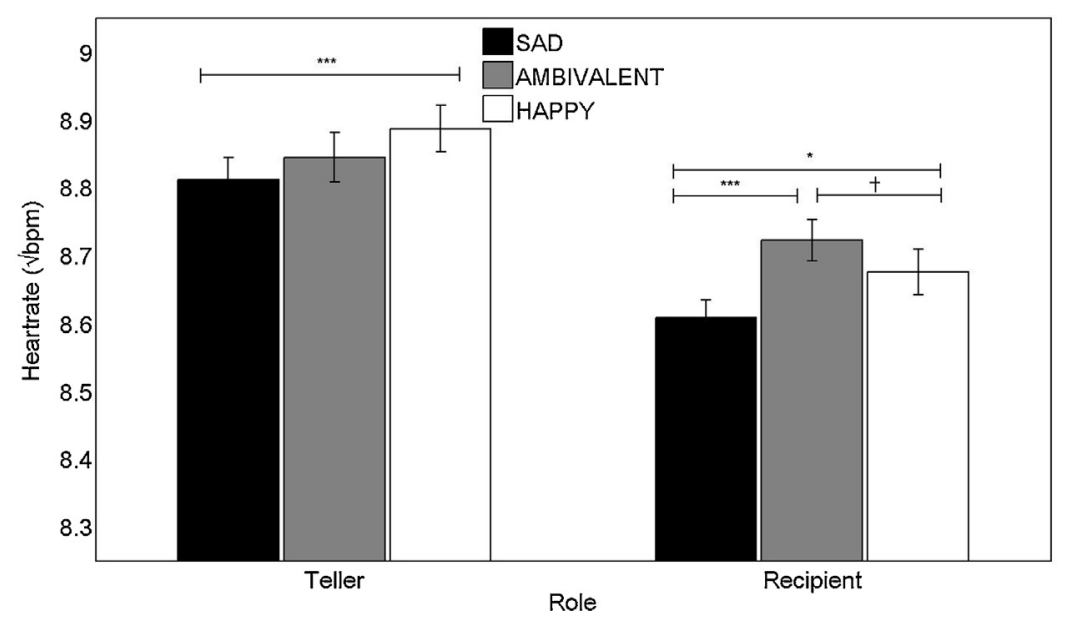

Fig. 3. Estimated means for heart rate. Error bars indicate $95 \%$ confidence intervals $\left({ }^{* * *} p<.001,{ }^{*} p<.05,{ }^{\dagger} .056\right.$ (trend), all values Bonferroni adjusted). 


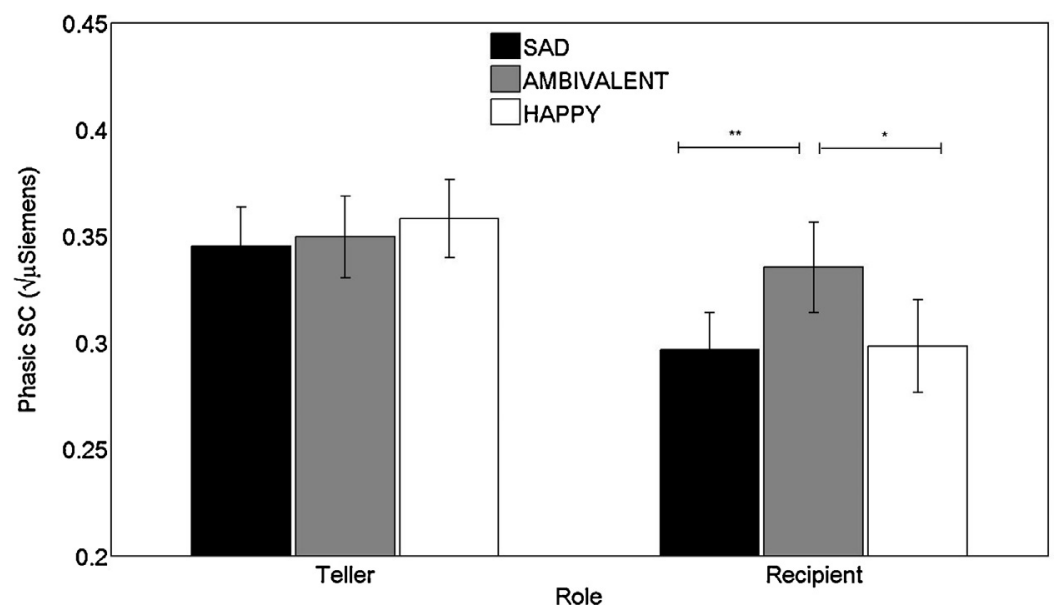

Fig. 4. Estimated means for phasic skin conductance. Error bars indicate $95 \%$ confidence intervals $\left({ }^{* *} p<.01\right.$, ${ }^{*} p<.05$, all values Bonferroni adjusted).

associated with smiling activity, and sad stories were most strongly associated with frowning activity. Ambivalent stories set in between the happy and the sad stories (expect in the case of EMG-CS, frown, in the teller). In the case of frowning activity during the sad stories, the recipient's activity was stronger than the teller's activity.

Furthermore, as expected, the participants' heart rate - one key indicator of arousal - was lower during the sad stories than during the happy or ambivalent stories. Somewhat contrary to our expectations, for skin conductance - another key indicator of arousal - there was no significant difference between the happy and the sad stories.

The results regarding heart rate and skin conductance during ambivalent stories are most important. Contrary to the facial EMG results, ambivalent stories elicited highest arousal as indexed by both heart rate and skin conductance in the recipient, but not in the teller.

\section{Discussion}

Earlier CA research has demonstrated ways in which linguistic and bodily displays of emotion are interactionally regulated (Goodwin et al., 2012; Ruusuvuori and Peräkylä, 2009; Kaukomaa et al., 2013). Our results further this line of research by showing a linkage between an interactional stance display and physiological indicators of emotion. The comparison of facial muscle activation (EMG) and heart rate in happy and sad stories showed a transparent connection between the affective stance displayed by the storyteller and indicators of physiological valence and arousal in the participants. The interactional stance is thus reflected in, facial muscle activation and an increase or a decrease of heart rate. This is in line with the dyadic system theory by Beebe and Lachmann (2002), suggesting that an interactional display of emotion by a participant is not only consequential for the overt behavior or the co-participant, but simultaneously, it is reflected in the physiological-emotional processes in both participants. Likewise, our results converge with the theory of emotional contagion (Hatfield et al., 1993) that links behavioral mimicry with emotional processes.

What was contrary to our expectations, then, was that ambivalent stories involved something more than merely a mixture of physiological indicators of positive and negative emotion. Regarding facial muscle activation and heart rate in the teller, ambivalent stories did set in between happy and sad stories. However, regarding arousal (HR and EDA) there was a difference between the effect of ambivalence on the teller and the recipient: ambivalent stance displayed by the teller increased the recipient's (but not the tellers) physiological arousal, compared to happy stance. In other words, ambivalent stance is somehow more arousing to the recipient than a salient happy or sad stance. Further empirical research, with more data segments, is needed to locate this effect. However, in a hypothetical manner, we would like to propose that besides emotional arousal linked to affiliating actions, the arousal in recipients during ambivalent stories might involve also activation that is linked to heightened attention and mental effort (Dawson et al., 2007; Furedy et al., 1996; Kahneman, 1973), having to do with the task of monitoring the presumably complex and intricate sequential implications of the ambivalent stance (cf. Ruusuvuori and Peräkylä, 2009; Hakulinen and Sorjonen, 2012).

Conversation analytical understanding of interaction involves that the participants constantly monitor each other's action in terms of their sequential implications: what kind of action is in question, what kind of response it makes relevant and how the response should be timed (e.g. Schegloff, 2007; Goodwin, 1980). In the case of storytelling, a preferred response is one that mirrors the teller's stance (Stivers, 2008; Jefferson, 1978). In the case of a story with an ambivalent stance, there are two possible stances (one positive and one negative), as well as the specific relation between these two 
stances (whether they are equal or whether one of the stances is more dominant or primary than the other) to be received. For example, in some cases affiliation with the teller can involve mirroring one of the stances but withholding the mirroring with the other, or modification of the stance in response. For example, in extract 4 shown earlier, the recipient affiliated more with the serious than with the humorous stance toward the teller's father. Our interpretation of the physiological arousal in the recipient is, then, that it reflects a more demanding cognitive and interactional task that the recipients face in monitoring the action of the teller and in affiliating with an ambivalent stance, compared to a salient positive or negative stance. In psychological terms, receiving an ambivalent story that may contain such "difficulties" as irony or disclosure of contradictive feelings perhaps demands more reasoning about the mental state of the co-participant (see Enfield and Levinson, 2006; Premack and Woodruff, 1978; Fonagy et al., 2002) or, from a more dialogical perspective (see Linell, 2009), perhaps more cognitive and interactional effort in collaborative construction of the narrative than is the case in responding to a saliently happy or sad story. This effect of ambivalence might be particularly strong in our data where the participants did not know each other before. However, these considerations are hypothetical in nature, and we suggest them to be taken under more detailed consideration in future studies. A neuroscientific study by Cunningham et al. (2003) is in line with the idea of the specific nature of ambivalence, as they suggest that response to an ambivalent stimulus involves more controlled evaluation processes, shown in prefrontal cortex activation, than a response to a stimulus with a simple valence that involves a more automatic process (see also Jung et al., 2008).

The analysis of the different story phases raises some questions for further research. Regarding the phases of the stories, we gained significant results considering the facial EMG-OO activation that is associated with smile and positive emotion: the activation is stronger in the climax and evaluation phases than in the buildup phases. Contrary to what could be expected, we did not find differences between the story phases in the physiological arousal. It is possible that such differences exist but the number of the events (stories) was too low, or the coding of the phases was too contingent for the differences between phases to appear. As was mentioned earlier, the coders found the coding of the phases difficult. For example, in many cases there were moments of heightened emotional expression that were followed by continuation of narration, and it was not easy for the coders to decide whether the moment of heightened emotion would be considered as the story climax (cf. Selting, 2010). The difficulty of deciding the borders of the story phases, as well as the distribution of physiological arousal throughout the story phases, suggests that like in written culture, also in conversation there is lot of variation between a prototypical story and the multiple ways in which experiences can be narrated (Ricoeur, 2004): emotion in storytelling may not be as much concentrated on a single, clear cut climax as we may have thought. The question about the possible differences in physiological activation during different story phases calls for further research.

On a general level, this study has demonstrated that CA and psychophysiological measurements can be combined, to study linkages between social interaction and autonomic nervous system activation. Methodologies that come from very different directions were brought together to yield novel results. The organization of ordinary interaction - in this case, the organization of stance displays in storytelling - resonates with the organization of the autonomic nervous system activation. From the perspective of interactional research, perhaps most interesting questions consider the changes in physiological activation of a participant of interaction that relate to the co-participant's conversational actions. The ANS activation can thus be considered as a further layer of stance mirroring (Stivers, 2008; Couper-Kuhlen, 2012) and mutual monitoring in storytelling interactions.

An effort to combine methods as different as CA and physiological measurement also brought about significant limitations to this study. To make CA communicate with statistical analysis inherent in psychophysiological research, coding and counting of events in interaction was necessary. Our coding scheme was not, and could not be, attentive to wide variety of important CA phenomena. One could even argue that our coding represents, a rather generic qualitative understanding of storytelling (see e.g. Labov and Waletzky, 1967), rather than a strictly CA take on stories. For example, the coding of the valence of stories yielded a "global" categorization of the valence and it was not meant to catch the moment-by-moment negotiation between the teller and the recipient regarding the direction of the story, which arguably is an important facet in conversational storytelling that would be of interest for CA researchers (cf. C. Goodwin, 1979; M.H. Goodwin, 1980.) Reliable coding is only possible through lumping phenomena together, and it is our belief that in spite of the fact that our coding does not preserve perhaps most of the CA understandings, through the little that it does preserve, it has entered into a fruitful dialog with the psychophysiological paradigm.

It should also be acknowledged that the data of this study was not naturalistic in the sense of conversation analytical tradition (Sacks, 1992). The setting was created for research purposes, the participants were "wired" and instructed to talk about their significant life events with a person who they did not know beforehand. On the other hand, our setting was not strictly experimental either. The events of interest (stories) were not controlled regarding their content, immediate environment, timing, length and number per speaker or conversation. Acknowledging the tension between the two different research traditions (naturalistic and experimental) we believe that this kind of hybrid setting made it possible for us to study physiological activation during conversation better than any other setting we could imagine. In the setting that was given to them, the participants of our study collaboratively created their conversations on topics that had emotional relevance. In CA terms, context of our data production involves as particular institutional setting (Heritage and Clayman, 
2010) which is distinctly different from ordinary conversation, but still involves orientation to basic conversational norms such as the relevance for response, tellability and topical continuity.

In this study, the analysis focused on an increase and decrease in activation in the teller and recipient during different types of events (stories with different valence). Another potential line of study for future is to investigate how interactional events relate to the concordance (synchrony) in physiological activation across the participants (see e.g. Levenson and Gottman, 1983; Marci et al., 2007; Feldman et al., 2011; Stephens et al., 2010).

Regarding the research setting, two lines of further development can be suggested. First, using a setting like ours, but with more detailed coding schemes, future research might explore more fine-grained linkages between social interaction and individual physiology or physiological synchrony between individuals. For example, a systematic analysis of the prosodic features of the talk could be included in the coding. Second, to further test our findings reported in this paper, strictly experimental studies could be designed. As the current study has delineated the phenomena of interest, a controlled experiment should be possible.

The amount of ambivalent stories - approximately as many as there were happy or sad stories - in a setting that was not geared to elicit ambivalence, was a surprise to us. Although our data are collected from a setting that was created for research purposes, it seems reasonable to argue that emotional ambivalence is much more common phenomenon in conversational storytelling than earlier interactional research has acknowledged (see however Ruusuvuori and Peräkylä, 2009; Hakulinen and Sorjonen, 2012). The fact that ambivalence is a common theme in literary narratives and drama (Hyvärinen, 2006; Ricoeur, 2004), and arguably also a common experience in close relations and everyday life (see Butler, 2008), suggests, likewise, that much of our everyday spoken narratives might involve ambivalence. Although our study does not respond to the problem of ambivalence that has been addressed in psychological and neuroscientific research - whether the ambivalence consists of simultaneous emotional feelings or rapid switching between feelings (Russell and Carroll, 1999; Larsen et al., 2001; Viinikainen et al., 2010, 2012), in a general level, our physiological results show that ambivalent stories are distinct from happy or sad ones, as our bodies respond to them in distinct ways. This all calls for further research on ambivalence in storytelling and in other domains of social interaction: as any other aspect of our generic human experience, also ambivalence is attended to and worked through in moment-by-moment social interaction.

\section{Acknowledgements}

We would like to thank Riitta Hari, John Heritage, Douglas W. Maynard, Federico Rossano, and the members of the Finnish Center of Excellence in Research on Intersubjectivity in Interaction for their helpful comments in the data sessions and seminars of the project. The research was funded by Academy of Finland (project 1132303) and the Finnish Centre of Excellence in Research on Intersubjectivity in Interaction.

\section{References}

Averill, James M., 1968. Grief: its nature and significance. Psychological Bulletin 70 (6), 721-748.

Bales, Robert F., 1950. Interaction Process Analysis. Addison-Wesley, Cambridge, MA.

Barrett, Lisa F., Russel, James A., 2009. Circumplex models. In: Sander, D., Scherer, K.R. (Eds.), The Oxford Companion to Emotion and the Affective Sciences. Oxford University Press, Oxford, pp. 85-88.

Barthes, Roland, 1977. Introduction to the structural analysis of narratives. In: Heath, S. (Ed.), Image/Music/Text, translated. Hill and Wang, New York, pp. 79-124.

Beebe, Beatrice, Lachmann, Frank M., 2002. Infant Research and Adult Treatment: Co-constructing Interactions. Analytic Press, Hillsdale, NJ.

Benedek, Mathias, Kaernbach, Christian, 2010. Decomposition of skin conductance data by means of nonnegative deconvolution. Psychophysiology 47, 647-658.

Berntson, Gary G., Quigley, Karen S., Lozano, Dave, 2007. Cardiovascular psychophysiology. In: Cacioppo, J.T., Tassinary, L.G., Berntson, G.G. (Eds.), Handbook of Psychophysiology. 3rd ed. Cambridge University Press, pp. 182-210.

Bradley, Margaret M., Lang, Peter J., 2007. Emotion and motivation. In: Cacioppo, J.T., Tassinary, L.G., Berntson, G.G. (Eds.), Handbook of Psychophysiology. 3rd ed. Cambridge University Press, pp. 581-607.

Butler, Judith, 2008. Taking another's view: ambivalent implications. In: Jay, M (Ed.), Axel Honneth, Reification: A New Look at an Old Idea. Oxford University Press, Oxford, pp. 97-119.

Cacioppo, John T., Berntson, Gary G., Larsen, Jeff T., Poehlmann, Kirsten M., Ito, Tiffany A., 2000. The psychophysiology of emotion. In: Lewis, R., Haviland-Jones, J.M. (Eds.), The Handbook of Emotion. 2nd ed. Guilford Press, New York, pp. 173-191.

Cohen, Jacob, 1968. Weighted kappa: nominal scale agreement with provision for scaled disagreement or partial credit. Psychological Bulletin 70 , 213-220.

Couper-Kuhlen, Elizabeth, 2012. Exploring affiliation in the reception of conversational complaint stories. In: Peräkylä, A., Sorjonen, M.-L. (Eds.), Emotion in Interaction. Oxford University Press, New York, pp. 113-146.

Cousineau, Denis, 2005. Confidence intervals in within-subject designs: a simpler solution to Loftus and Masson's method. Tutorials in Quantitative Methods for Psychology 1, 75-78.

Cunningham, William A., Johnson Marcia, K., Gatenby Chris, J., Gore John, C., Banaji Mahzarin, R., 2003. Neural components of social evaluation. Journal of Personality and Social Psychology 85, 639-649. 
Dawson, Michael E., Schell, Anne M., Filion Diane, L., 2007. The electrodermal system. In: Cacioppo, J.T., Tassinary, L.G., Berntson, G.G. (Eds.), Handbook of Psychophysiology. 3rd ed. Cambridge University Press, pp. 159-181.

De Carvalho, João L.A., Da Rocha, Adson F., Nascimento, Francisco A.O., Neto, João S., Junqueira, Luiz F., 2002. Development of a Matlab software for analysis of heart rate variability. In: Proceedings 6th International Conference on Signal Processing, vol. 2, pp. $1488-1491$.

DiMascio, Alberto, Boyd, Richard W., Greenblatt, Milton, 1957. Physiological correlates of tension and antagonism during psychotherapy: a study of interpersonal physiology. Psychosomatic Medicine 19, 99-104.

Elkins, Amanda N., Mutha, Eric R., Hooverb, Adam W., Walkera, Alexander D., Carpentera, Thomas L., 2009. Physiological compliance and team performance. Applied Ergonomics 40 (6), 997-1003.

Enfield, Nicholas J., Levinson, Stephen C., 2006. Introduction: human sociality as a new interdisciplinary field. In: Enfield, N.J., Levinson, S.C. (Eds.), Roots of Human Sociality: Culture, Cognition and Interaction. Berg, New York, pp. 1-35.

Feldman, Ruth, Magori-Cohen, Romi, Galili, Giora, Singer, Magi, Louzoun, Yoram, 2011. Mother and infant coordinate heart rhythms through episodes of interaction synchrony. Infant Behavior \& Development 34, 569-577.

Fonagy, Peter, Gergely, Gyorgy, Jurist, Elliot L., 2002. Affect Regulation, Mentalization and the Development of the Self. Other Press, New York.

Fridlund, Alan J., Cacioppo, John T., 1986. Guidelines for human electromyographic research. Psychophysiology 23, 567-589.

Furedy, John J., Szabo, Attila, Peronnet, Francois, 1996. Effects of psychological and physiological challenges on heart rate, T-wave amplitude, and pulse-transit time. International Journal of Psychophysiology 22 (3), 173-183.

Gehricke, Jean-Guido, Fridlund, Alan J., 2002. Smiling, frowning, and autonomic activity in mildly depressed and non-depressed men in response to emotional imagery of social contexts. Perceptual and Motor Skills 94 (1), 141-151.

Goffman, Erving, 1983. Interaction order. American Sociological Review 48, 1-43.

Goodwin, Charles, 1979. The interactive construction of a sentence in natural conversation. In: Psathas, G. (Ed.), Everyday Language: Studies in Ethnomethodology. Irvington Publishers, New York, pp. 97-121.

Goodwin, Marjorie H., 1980. Processes of mutual monitoring implicated in the production of description sequences. Sociological Inquiry 50 , 303-317.

Goodwin, Charles, Goodwin, Marjorie H., 2000. Emotion within situated activity. In: Duranti, A. (Ed.), Linguistic Anthropology: A Reader. Blackwell, Malden, MA. (reprint of paper in Budwig et al.), pp. 239-257.

Goodwin, Marjorie H., Cekaite, Asta, Goodwin, Charles, 2012. Emotion as stance. In: Peräkylä, A., Sorjonen, M.-L. (Eds.), Emotion in Interaction. Oxford University Press, New York, pp. 16-41.

Gross, James J., Fredrickson, Barbara L., Levenson, Robert W., 1994. The psychophysiology of crying. Psychophysiology 31, 460-468.

Hakulinen, Auli, Sorjonen, Marja-Leena, 2012. Being equivocal: affective responses left unspecified. In: Peräkylä, A., Sorjonen, M.-L. (Eds.), Emotion in Interaction. Oxford University Press, New York, pp. 147-173.

Hatfield, Elaine, Cacioppo, John T., Rapson, Richard L., 1993. Emotional Contagion. Cambridge University Press, New York.

Henning, Robert A., Boucsein, Wolfram, Gil Monica, C., 2001. Social-physiological compliance as a determinant of team performance. International Journal of Psychophysiology 40, 221-232.

Heritage, John, Clayman, Steven, 2010. Talk in Action: Interactions, Identities, and Institutions. Wiley-Blackwell, West Sussex.

Hyvärinen, Matti, 2006. Kerronnallinen tutkimus (Narrative Research). http://www.hyvarinen.info/material/Hyvarinen-Kerronnallinen_tutkimus.pdf (accessed 04.06.13).

Jefferson, Gail, 1978. Sequential aspects of storytelling in conversation. In: Schenkein, J.N. (Ed.), Studies in the Organization of Conversational Interaction. Academic Press, New York, pp. 213-248.

Jefferson, Gail, 1980. On trouble-premonitory response to inquiry. Sociological Inquiry 50, 153-185.

Jefferson, Gail, 1984. On the organization of laughter in talk about troubles. In: Atkinson, J.M., Heritage, J.C. (Eds.), Structures of Social Action: Studies in Conversation Analysis. Cambridge University Press, Cambridge, UK, pp. 346-369.

Jung, Young-Chul, Park, Hae-Jeong, Kim, Jae-Jin, Chun, Ji Won, Kim, Hye Sun, Kim, Nam Wook, Son, Sang Jun, Oh, Maeng-Gun, Lee, Jong Doo, 2008. Reciprocal activation of the orbitofrontal cortex and the ventrolateral prefrontal cortex in processing ambivalent stimuli. Brain Research 1246, 136-143.

Kahneman, Daniel, 1973. Attention and Effort. Prentice-Hall, Englewood Cliffs, NJ.

Kaukomaa, Timo, Peräkylä, Anssi, Ruusuvuori, Johanna, 2013. Turn-opening smiles: Facial expression constructing emotional transition in conversation. Journal of Pragmatics 55, 21-42.

Kreibig, Sylvia D., 2010. Autonomic nervous system activity in emotion: a review. Biological Psychology 84, $394-421$.

Kupetz, Maxi, 2014. Empathy displays as interactional achievements-Multimodal and sequential aspects. Journal of Pragmatics 61, 4-34.

Labov, William, Waletzky, Joshua, 1967. Narrative analysis: oral versions of personal experience. In: Helm, I. (Ed.), Essays on the Verbal and Visual Arts: Proceedings of the 1966 Annual Spring Meeting of the American Ethnological Society, pp. 12-44.

Landis, Richard J., Koch, Gary G., 1977. The measurement of observer agreement for categorical data. Biometrics 33 (1), 159-174.

Larsen, Randy J., Diener, Edward, 1992. Promises and problems with the circumplex model of emotion. In: Clark, M. (Ed.), Review of personality and social psychology, vol. 13. Sage, Newbury Park, CA, pp. 25-59.

Larsen, Jeff, McGraw, Peter A., Cacioppo, John T., 2001. Can people feel happy and sad at the same time? Journal of Personality and Social Psychology 81, 684-696.

Larsen, Jeff, Berntson, Gary, Poehlmann, Kirsten, Ito, Tiffany, Cacioppo, John T., 2008. The psychophysiology of emotion. In: Lewis, M., Haviland-Jones, J., Feldman, B.L. (Eds.), Handbook of Emotions. Guilford Press, New York, pp. 180-195.

Levenson, Robert W., Gottman, John M., 1983. Marital interaction: physiological linkage and affective exchange. Journal of Personality and Social Psychology 45 (3), 587-597.

Levenson, Robert W., Carstensen, Laura L., Friesen, Wallace V., Ekman, Paul, 1991. Emotion, physiology, and expression in old age. Psychology and Aging 6, 28-35.

Linell, Per, 2009. Rethinking Language, Mind and World Dialogically: Interactional and contextual theories of human sense-making. Information Age Publishing, Charlotte, NC.

Marci, Carl D., Ham, Jacob, Moran, Erin, Orr, Scott P., 2007. Physiologic correlates of perceived therapist empathy and social-emotional process during psychotherapy. Journal of Nervous and Mental Disorder 195 (2), 103-111. 
Maynard, Douglas W., 2003. Bad News, Good News: Conversational Order in Everyday Talk and Clinical Settings. University of Chicago Press, Chicago.

Peräkylä, Anssi, 2012. Epilogue: what does the study of interaction offer to emotion research. In: Peräkylä, A., Sorjonen, M.-L. (Eds.), Emotion in Interaction. Oxford University Press, New York, pp. 274-289.

Peräkylä, Anssi, Ruusuvuori, Johanna, 2012. Facial expression and interactional regulation of emotion. In: Peräkylä, A., Sorjonen, M.-L. (Eds.), Emotion in Interaction. Oxford University Press, New York, pp. 64-91.

Peräkylä, A., Henttonen, P., Voutilainen, L., Kahri, M., Stevanovic, M., Sams,M., Ravaja, N. (submitted). Recipient affiliation calms down the storyteller.

Premack, David G., Woodruff, Guy, 1978. Does the chimpanzee have a theory of mind? Behavioral and Brain Sciences 1 (4), 515-526.

Ricoeur, Paul, 2004. Memory, History, Forgetting. Chicago University Press, Chicago.

Rottenberg, Jonathan, Kasch, Karen L., Gross, James J., Gotlib, lan H., 2002. Sadness and amusement reactivity differentially predict concurrent and prospective functioning in major depressive disorder. Emotion 2, 135-146.

Russell, James A., 1980. A circumplex model of affect. Journal of Personality and Social Psychology 39, 1161-1178.

Russell, James A., Carroll, James M., 1999. On the bipolarity of positive and negative affect. Physiological Bulletin 125, 3-30.

Ruusuvuori, Johanna, Peräkylä, Anssi, 2009. Facial and verbal expressions in assessing stories and topics. Research on Language and Social Interaction 42 (4), 377-394.

Sacks, Harvey, 1974. An analysis of the course of a joke's telling in conversation. In: Bauman, R., Sherzer, J.F. (Eds.), Explorations in the Ethnography of Speaking. Cambridge University Press, Cambridge, UK, pp. 337-353.

Sacks, Harvey, 1992. Lectures on Conversation. Blackwell, Oxford.

Sacks, Harvey, Schegloff, Emanuel A., Jefferson, Gail, 1974. A simplest systematics for the organisation of turn-taking for conversation. Language 50, 696-735.

Schegloff, Emanuel, 2007. Sequence Organization in Interaction. A Primer in Conversation Analysis. Cambridge University Press, Cambridge.

Selting, Margaret, 2010. Affectivity in conversational storytelling: an analysis of displays of anger or indignation in complaint stories. Pragmatics 20, 229-277.

Sim, Julius, Wright, Chris C., 2005. The kappa statistic in reliability studies: use, interpretation, and sample size requirements. Physical Therapy 85 (3), 257-268.

Sorjonen, Marja-Leena, Peräkylä, Anssi, 2012. Introduction. In: Peräkylä, A., Sorjonen, M.-L. (Eds.), Emotion in Interaction. Oxford University Press, New York, pp. 3-15.

Stephens, Greg J., Silbert, Lauren J., Hasson, Uri, 2010. Speaker-listener neural coupling underlies successful communication. PNAS 107, $14425-14430$.

Stivers, Tanya, 2008. Stance, alignment, and affiliation during storytelling: when nodding is a token of affiliation. Research on Language and Social Interaction 41 (1), 31-57.

Toivonen, Riitta, Kivelä, Mikko, Saramäki, Jari, Viinikainen, Mikko, Vanhatalo, Maija, Sams, Mikko, 2012. Networks of emotion concepts. PLOS ONE 7, e28883.

Viinikainen, Mikko, Jääskeläinen, liro P., Alexandrov, Yuri, Balk, Marja H., Autti, Taina, Sams, Mikko, 2010. Nonlinear relationship between emotional valence and brain activity: evidence of separate negative and positive valence dimensions. Human Brain Mapping 31 (7), $1030-1040$.

Viinikainen, Mikko, Glerean, Enricom, Jääskeläinen, liro P., Kettunen, Juho, Sams, Mikko, Nummenmaa, Lauri, 2012. Nonlinear neural representation of emotional feelings elicited by dynamic naturalistic stimulation. Open Journal of Neuroscience 2 (1), 2-4.

Villmann, Thomas, Liebers, Christiane, Bergmann, Beate, Gumz, Antje, Geyer, Michael, 2008. Investigation of psycho-physiological interactions between patient and therapist during a psychodynamic therapy and their relation to speech using in terms of entropy analysis using a neural network approach. New Ideas in Psychology 26, 309-325.

Vrana, Scott R., Gross, Daniel, 2004. Reactions to facial expressions: effects of social context and speech anxiety on responses to neutral, anger and joy expressions. Biological Psychology 66, 63-78.

Liisa Voutilainen is Postdoctoral researcher in the Finnish Centre of Excellence in Research on Intersubjectivity in Interaction, University of Helsinki. She has previously published CA research on interactional management of emotion in psychotherapy.

Pentti Henttonen is Doctoral student in the Finnish Centre of Excellence in Research on Intersubjectivity in Interaction, University of Helsinki. The topic of his doctoral dissertation is physiological dynamics of conversation.

Mikko Kahri is Doctoral student in the Finnish Centre of Excellence in Research on Intersubjectivity in Interaction, University of Helsinki. The topic of his doctoral dissertation is infant-caretaker interaction.

Maari Kivioja is Clinical psychologist in Outward Psychiatric Clinic of Western Helsinki. Previously she worked as Research assistant at the Department of Social Research, University of Helsinki, in the research project that this paper is based on.

Niklas Ravaja is Professor of Social Psychology at the University of Helsinki. He has previously published on emotional and psychophysiological processes during non-mediated and mediated social interaction.

Mikko Sams is Professor of Cognitive Neuroscience at Aalto University. He has previously published on neurocognitive mechanisms of speech, attention, emotions and social behavior.

Anssi Peräkylä is Professor of Sociology at the University of Helsinki, and the vice-director of the Finnish Centre of Excellence in Research on Intersubjectivity in Interaction. He has previously published studies on medical consultations, psychotherapy, and emotion in interaction. 